\section{Gardening Information on Television and Radio in Japan Based on Surveys in 1981 and 1996}

\author{
Eisuke Matsuo, Hyojung Kweon, \\ Fusayo Asano, and Youko Yoshida
}

Additional INDEX words. gardening programming, current event news

Summary. Television and radio are efficient means through which Japanese obtain gardening information. Broadcasting stations were surveyed on the status of gardening programming, year of commencement, length and number of programs, and time and day of broadcasting in 1981 and 1996. Surveys showed that gardening programming increased from the middle $1970 \mathrm{~s}$ and the late 1980s. These periods roughly correspond with the gardening boom in Japan. The length of gardening programs tended to shorten. On television, broadcasting was more concentrated on weekend mornings in 1996 than 1981, while the concentration of the day and time was less on radio.

$\mathrm{F}$ rom the $1970 \mathrm{~s}$ to the present, about $30 \%$ of the Japanese population consistently has been interested in gardening (Matsuo, 1995). Thus we can say that gardening is not a fashion, but a lifestyle (Matsuo, 1995). Businesses related to plants, materials and tools for gardening are prospering; and information sources such as magazines and books on gardening are increasing (Matsuo, 1996; Matsuo, 1997).

On television and radio, gardening information is available cheaply and conveniently. This paper addresses the change in gardening information on television and radio in Japan, based on surveys in 1981 and 1996.

Division of Applied Plant Science, Department of Plant Resources, Faculty of Agriculture, Kyushu University, Fukuoka, 812-8581, Japan.

The cost of publishing this paper was defrayed in part by the payment of page charges. Under postal regulations, this paper therefore must be hereby marked advertisement solely to indicate this fact.

\section{Methods of research}

In July 1981 and Oct. 1996, questionnaires were sent to broadcasting stations, excluding music stations, television shopping channels, and regional, "small-town" stations. Responses were received until Aug. 1981 and Dec. 1996, respectively. A gardening program was defined as one relating to gardening, agriculture, plants and flowers, or greenery. A regular program was defined as one broadcast at one or more appointed times per week. Listings of regular gardening programs in subject television and radio program guides were examined in newspapers prior to each survey.

\section{Results and conclusion}

Thirty-seven television and radio stations broadcast regular gardening programs in both 1981 and 1996 (Table 1). However, there were 147 stations responding in 1981, compared to 204 in 1996. Thus, the ratio of stations with regular gardening programs to all stations responding decreased from $25.2 \%$ in 1981 to $18.1 \%$ in 1996 . More regular garden programs were broadcast on television than radio in both 1981 and 1996.

The effect of the combination of visual and auditory sensory input from television on viewers was greater than the effect of the auditory-only effect of radio (Matsuo, 1982). Children preferred the medium of television, and perceived it as more realistic and easier to learn from (Salomon, 1984; Stack, 1997). These may explain partially why there were more television than radio programs in Japan.

The number of television and radio broadcasting stations with regular gardening programs is shown in Fig. 1. Programming increased sharply from the mid-1970s to the early 1980 s, with the increase in radio programming preceding the increase in television programming. This trend corresponded with the issuing of new magazines (Matsuo, 1995). Since the late 1980s, there has been another such increase. These periods roughly corresponded with the gardening booms in the 1970s and the late 1980s.

On both television and radio, the total length of regular gardening programs per week per station shortened (Table $2)$. Some stations broadcast over $51 \mathrm{~min}$ of gardening programming per week in 1981, but none did so in 1996. In both 1981 and 1996 a large number of television stations (58\% in 1981 and $75 \%$ in 1996) broadcast between 11 and $21 \mathrm{~min} /$ week. On radio, between 11 and $21 \mathrm{~min} /$ week were broadcast $(55 \%)$ in 1981 , decreasing to between 1 and $11 \mathrm{~min} /$ week $(77 \%)$ in 1996.

On radio, the number of 5 to 10 -min programs in-

Table 1. Number of television (TV) and radio broadcasting stations responding and percentage having garden programs.

\begin{tabular}{|c|c|c|c|c|c|c|c|}
\hline \multirow[b]{2}{*}{ Year } & \multirow[b]{2}{*}{ Station } & \multirow[b]{2}{*}{ Examined } & \multirow[b]{2}{*}{ Responding } & \multicolumn{2}{|c|}{ Regular $^{\mathrm{z}}$} & \multicolumn{2}{|c|}{ Semiregular ${ }^{y}$} \\
\hline & & & & No. & $\%^{x}$ & No. & $\%^{x}$ \\
\hline \multirow[t]{2}{*}{1981} & $\mathrm{TV}$ & 96 & 94 & 26 & 27.6 & 5 & 5.3 \\
\hline & Total & 150 & 147 & 37 & 25.2 & 10 & 6.8 \\
\hline \multirow[t]{2}{*}{1996} & TV & 127 & 117 & 24 & 20.5 & 2 & 1.7 \\
\hline & Radio & 90 & 87 & 13 & 14.9 & 1 & 1.1 \\
\hline
\end{tabular}

zProgram broadcast more than once per week.

yprogram broadcast once or twice per month, or irregularly.

xercentage of broadcasting stations with gardening programs to responding stations. 


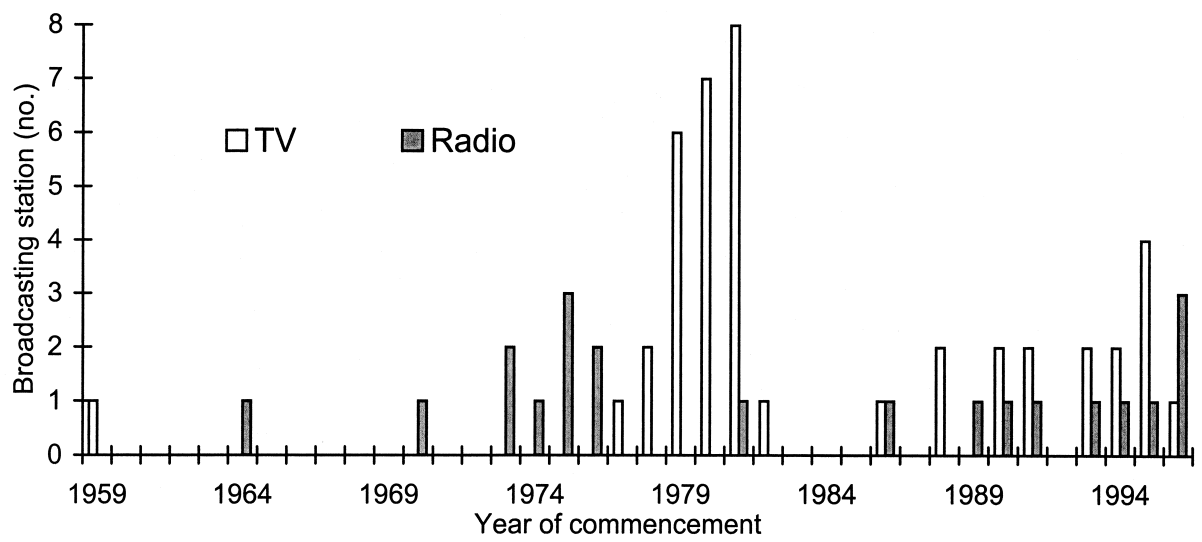

gardening topics were included in current event news, frequently resulting in short program length, compared to the independent gardening program.

Many television gardening programs were broadcast on Saturday morning and Sunday (Fig. 2). Broadcasting time decreased from $635 \mathrm{~min}$ in 1981 to $437 \mathrm{~min}$ in 1996 (Table 4). There were more broadcasts and more program minutes on the weekend in 1996 than in 1981. Also, there were many weekday programs in 1981 , but only a few in 1996. Usually people who love gardening wake up early and take

Fig. 1. Year of commencement of regular gardening programs on television (TV) and radio.

creased, with more than half of them answering questions about gardening, called in live by telephone from the listening audience. According to the questionnaire answers, radio did not communicate visually, and listeners were more likely to be bored, in contrast with television. Answers also indicated that the interactive telephone question and answer format tended to hold the listeners' attention to a greater extent.

The length of regular gardening programs is shown in Table 3. In both 1981 and 1996 the mean length of a television program was approximately $14 \mathrm{~min}$. However, the total number of programs decreased from 49 in 1981 to 26 in 1996, because programs that had been broadcast five times per week were gone in 1996.

On radio, the mean program length decreased from 1981 (14.4 $\mathrm{min})$ to $1996(6.4 \mathrm{~min})$. The total number of programs was 16 in 1981 and 28 in 1996. Programs 6, 10, and $15 \mathrm{~min}$ in length were preferred in 1981. However in 1996, there were numerous 5-min programs $(68 \%)$, and there was no program over $15 \mathrm{~min}$. In the case of radio, care of their plants in the morning. It appears that broadcasting stations arrange their gardening programs on weekend mornings (Fig. 2), so people can garden immediately after viewing the program.

In contrast to television, radio gardening programs are not concentrated on Saturdays and Sundays. The difference in the number of programs per day during the week was low in 1981, but in 1996, programs were slightly concentrated on Tuesdays and Saturdays. In 1981 most programs were placed between 1000 HR and 1200 HR, but less so in 1996 . Stations commented in the survey in 1981 that program listeners were housewives and the elderly, who were able to listen to radio at that time. However, in 1996 the audience of the programs included, in addition to housewives and the elderly, people working on farms and businesses.

In 1981 there were 16 radio programs per week, and in 1996 there were 28 (Table 4). However, total gardening programming minutes decreased 22\% from 1981 to 1996. The cause for the decrease was an increase in current event news that included short gardening programs. Such programming may have increased because people listen to the radio at work.

On television, there were seven gardening program

Table 2. Total length of garden programs and number of stations with regular garden programs per week.

\begin{tabular}{|c|c|c|c|c|c|c|c|c|c|}
\hline \multirow[b]{2}{*}{ Station } & \multirow[b]{2}{*}{ Year } & \multicolumn{8}{|c|}{ Min/station } \\
\hline & & $1-10$ & 11-20 & 21-30 & $31-40$ & 41-50 & $51-60$ & $61-70$ & 71-80 \\
\hline TV & 1981 & 3 & 15 & 3 & 0 & 0 & 1 & 0 & 4 \\
\hline \multirow[t]{2}{*}{ Radio } & 1981 & 2 & 6 & 2 & 0 & 0 & 1 & 0 & 0 \\
\hline & 1996 & 10 & 1 & 0 & 0 & 2 & 0 & 0 & 0 \\
\hline
\end{tabular}

Table 3. Numbers of television (TV) and radio garden programs in relation to broadcast length of one regular garden program.

Program duration

(min)

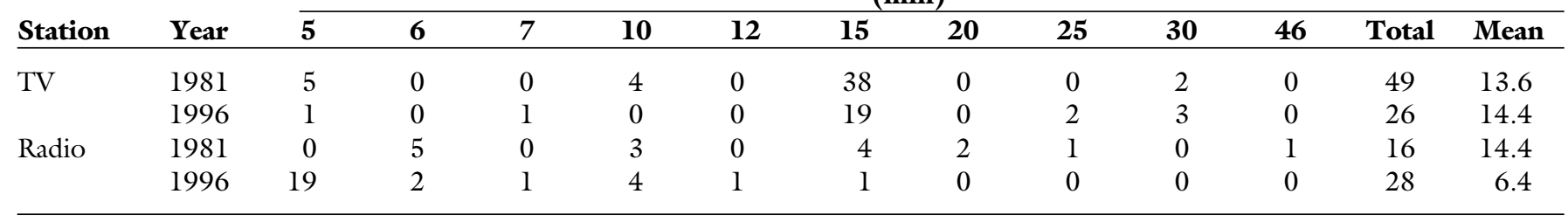




\section{TV}
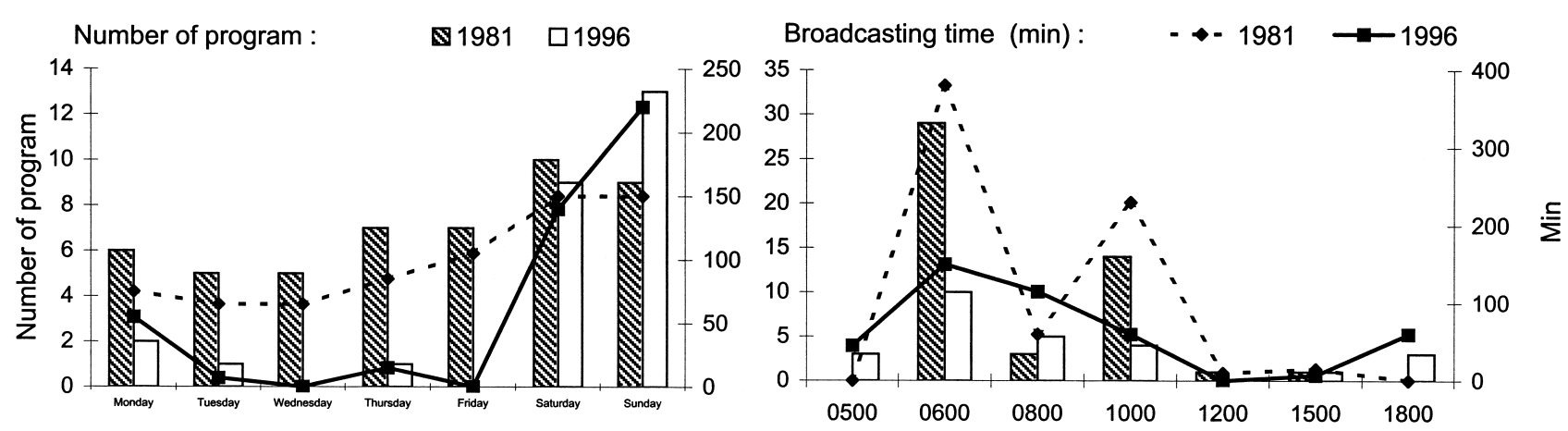

Radio
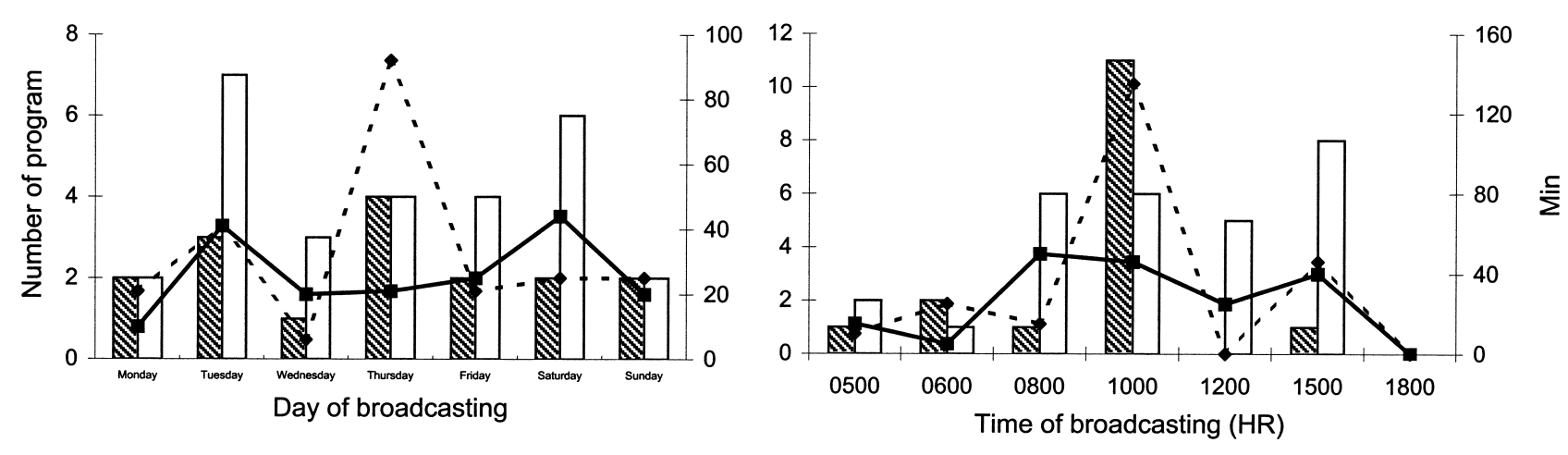

Fig. 2. Day and time of broadcasting and broadcast length of regular gardening programs on television (TV) and radio.

Table 4. Number of program titles, number of programs per week and total gardening programming minutes on television (TV) and radio.

\begin{tabular}{lccccc}
\hline Medium & Year & $\begin{array}{c}\text { No. of } \\
\text { stations } /\end{array}$ & $\begin{array}{c}\text { No. of } \\
\text { program } \\
\text { titles }\end{array}$ & $\begin{array}{c}\text { No. of } \\
\text { programs/ } \\
\text { week }\end{array}$ & $\begin{array}{c}\text { Total } \\
\text { gardening } \\
\text { programming } \\
\text { min }\end{array}$ \\
\hline TV & 1981 & 26 & 7 & 46 & 635 \\
Radio & 1996 & 11 & 5 & 26 & 437 \\
& 1981 & 24 & 8 & 16 & 231 \\
\hline
\end{tabular}

${ }^{{ }^{z}}$ Stations with regular gardening programs.

titles in 1981, and five in 1996 (Table 4). Many stations with regular gardening programs (68\% in 1981 and $72 \%$ in 1996$)$ telecast the same program ("Tanoshii Engei"), because local stations purchase programs from other stations. This may be done to reduce expensive production costs.

There were more regular gardening programs on radio than there were on television. On radio, gardening is taken up in telephone counseling, generally resulting in low program production costs. So each station can easily produce its own program with local topics addressed. Thus, the trend in radio programming changed from 1981 to 1996 , and the number of regular programs increased from 7 in 1981 to 17 in 1996, including 7 current event news programs that dealt with gardening topics in 1996.

\section{Literature cited}

Matsuo, E. 1982. Katei engei ni kansuru kenkyu 3. TV to radio ni yoru engei joho. J. Jpn. Soc. Hort. Sci. 51(2):334-335 (Abstr.).

Matsuo, E. 1995. Amateur engei no sengo 50nen wo miru, p. 284296. In: Y. Tsukamoto (ed.). Engei no seiki 1. Hana wo tsukuru. Yasakashobo, Tokyo.

Matsuo, E. 1996. Engeiryoho ni kansuru saikin no doko to engei no ryohoteki riyo no jitsujo. Green joho 17(4):16-17.

Matsuo, E. 1997. Kurashi to noko. Shimin no engei wo kangaeru 1. Agr. Hort. 72(1):9-14.

Salomon, G. 1984. Television is "easy" and print is "tough:" The differential investment of mental effort in learning as a function of perceptions and attribution. J. Educ. Psychol. 76:647-658.

Stack, L.B. 1997. Interactive television delivers Master Gardener training effectively. HortTechnology 7(4):357-359. 